\title{
Phase II trial of isoflavone in prostate-specific antigen recurrent prostate cancer after previous local therapy
} John M Pendleton ${ }^{1}$, Winston W Tan ${ }^{2}$, Satoshi Anai ${ }^{1}$, Myron Chang3, Wei Hou ${ }^{3}$, Kathleen T Shiverick ${ }^{4}$ and Charles J Rosser*1

Address: ${ }^{1}$ Division of Urology, The University of Florida, Jacksonville, Florida 32209, USA, 2Department of Hematology-Oncology, Mayo Clinic, Jacksonville, FL 32224, USA, ${ }^{3}$ Department of Epidemiology and Health Policy Research, The University of Florida, Gainesville, Florida 32610, USA and ${ }^{4}$ Department of Pharmacology, The University of Florida, Gainesville, Florida 32610, USA

Email: John M Pendleton - john.pendleton@jax.ufl.edu; Winston WTan - winston.tan@mayo.edu; Satoshi Anai - satoshi@urology.ufl.edu; Myron Chang - MChang@childrensoncologygroup.org; Wei Hou - whou@biostat.ufl.edu; Kathleen T Shiverick - kshiverick@ufl.edu; Charles J Rosser* - charles.rosser@urology.ufl.edu

* Corresponding author

Published: II May 2008

BMC Cancer 2008, 8:132 doi:10.1 186/147|-2407-8-132
Received: 17 December 2007

Accepted: II May 2008

This article is available from: http://www.biomedcentral.com/I47I-2407/8//32

(C) 2008 Pendleton et al; licensee BioMed Central Ltd.

This is an Open Access article distributed under the terms of the Creative Commons Attribution License (http://creativecommons.org/licenses/by/2.0), which permits unrestricted use, distribution, and reproduction in any medium, provided the original work is properly cited.

\begin{abstract}
Background-: Data exist that demonstrate isoflavones' potent antiproliferative effects on prostate cancer cells. We evaluated the efficacy of isoflavone in patients with PSA recurrent prostate cancer after prior therapy. We postulated that isoflavone therapy would slow the rate of rise of serum PSA.
\end{abstract}

Methods-: Twenty patients with rising PSA after prior local therapy were enrolled in this openlabeled, Phase II, nonrandomized trial (Trial registration \# NCT00596895). Patients were treated with soy milk containing $47 \mathrm{mg}$ of isoflavonoid per 8 oz serving three times per day for 12 months. Serum PSA, testosterone, lipids, isoflavone levels (genistein, daidzein, and equol), and quality of life (QOL) were measured at various time points from 0 to 12 months. PSA outcome was evaluated.

Results-: Within the mixed regression model, it was estimated that PSA had increased $56 \%$ per year before study entry and only increased $20 \%$ per year for the 12-month study period $(p=0.05)$. Specifically, the slope of PSA after study entry was significantly lower than that before study entry in 6 patients and the slope of PSA after study entry was significantly higher than before study entry in 2 patients. For the remaining 12 patients, the change in slope was statistically insignificant. Nearly two thirds of the patients were noted to have significant levels of free equol in their serum while on therapy.

Conclusion-: Dietary intervention with isoflavone supplementation may have biologic activity in men with biochemical recurrent prostate cancer as shown by a decline in the slope of PSA. This study may lend support to the literature that nutritional supplements have biologic activity in prostate cancer and therefore, further studies with these agents in randomized clinical trials should be encouraged. 


\section{Background}

Environmental factors have been investigated as possible etiologic influences for the development of prostate cancer, including occupational exposures, smoking, alcohol consumption, sexual practices, venereal transmitted diseases, and vasectomy. Only dietary influences have shown any promise[1]. The most provocative data supporting the influence of dietary factors on the clinical incidence of prostate cancer come from international studies and from studies of disease expression in immigrant populations. Historically, the incidence of prostate cancer in Japan has been extremely low. However, as Japanese men migrate to Hawaii or the U.S. mainland and subsequently adopt a western culture, their incidence of prostate cancer rapidly approaches that of Caucasian Americans [3,4]. The diets of native Chinese and Japanese are rich in fiber and low in saturated fat. These cultural differences may contribute to the lower rates of clinical prostate cancer in the Far East compared to Northern Europe and North America. In addition, recent evidence suggests that soy consumption contributes to the lower clinical incidence of prostate cancer in Asian countries [5].

One of the several compounds in soy is isoflavone, a soybean protease inhibitor. In vitro experimental data suggest that isoflavones are cancer preventive agents [6]. Genistein glycosides account for more than two-thirds of the total soybean isoflavone content [7]. Genistein is known to inhibit both androgen-dependent and androgen-independent prostate cancer cell growth in vitro. It is speculated that the mechanisms by which genistein exerts its effect are related to the inhibition of protein tyrosine kinase, DNA topoisomerases, angiogenesis, as well as its effect on cellular differentiation and apoptosis [8].

Daidzein is another major constituent of total soybean isoflavone content. It is speculated that some humans possess the necessary intestinal flora to convert daidzein to equol, a molecule similar to estrogen [9]. Thus, isoflavones may act through hormonal manipulation. If isoflavones change the hormonal milieu, it is quite possible that their mechanism of action is centered on the androgen receptor (AR). AR activity has been implicated as pivotal in several phases of prostate cancer: origin, transition to androgen independent status, and progression. Linkage studies suggest that the activity of the AR might be correlated with tumor incidence and aggressiveness. Researchers have found that a decreased repeat length of an AR polymorphism correlates with an increased risk of and aggressiveness of prostate cancer [10].

We set out to determine if dietary supplementation is indeed a potential therapeutic option, by evaluating the efficacy of isoflavone in subjects with prostate-specific antigen (PSA) recurrent prostate cancer after radiation therapy or radical prostatectomy. Herein, we report the serum PSA, CAG androgen receptor polymorphism, and quality of life results of our phase II, prospective study.

\section{Methods}

This study was performed after review and approval by the Institutional Review Board of the University of Florida at Jacksonville, an inner-city hospital serving Duval County. The study was an investigator initiated, industry sponsored (Hain-Celestial, Denver CO), phase II, non-randomized clinical trial. The study was registered with National Institute of Health (registration \# NCT00596895).

\section{Study Design}

Sample size determination to detect a reduction of $10 \%$ in PSA from initial levels [actual calculation as $\log _{10}$ (PSA) with a standard deviation of $37 \%$ of PSA level] required 27 patients to have a significance of $\mathrm{p}=0.05$ and a power of $60 \%$. However, due to poor accrual, the study was closed after the enrollment of 20 patients. With the sample size of 20 , a reduction of $12 \%$ in PSA can be detected with the same significance level and power.

Twenty patients were enrolled in this study from May 2004 to January 2007. Eligibility criteria included: able to give informed consent, adenocarcinoma of the prostate (no small cell component), and prior treatment with radiation (at least $6200 \mathrm{cGy}, \mathrm{n}=9$ ) or radical prostatectomy $(\mathrm{n}=11)$ for clinically localized disease (clinical T1 or T2). Table 1 shows the demographic, clinical, and pathologic characteristics of the study cohort. All patients had demonstrated evidence of biochemical failure within a median of $6 \pm 3$ years after treatment. Biochemical failure was defined as a) detectable and rising PSA after surgery or b) three consecutive PSA rises after radiation therapy [11].

Patients could not have demonstrable and/or histologically confirmed metastatic or locally recurrent disease demonstrated on bone scan, computed tomography or transrectal ultrasound, or be clinically symptomatic at the time of enrollment. Patients could have received androgen deprivation therapy (ADT), but not within 12 months of entry into the study. In addition, patients had to have a life expectancy of at least one year and performance status of $<2$ of Zubrod scale. Patients with a known allergic reaction to milk or soy products were excluded.

Twenty men who have had evidence of biochemical relapse after radiation therapy and/or prostatectomy comprised the study cohort. These patients ingested Soy Dream Enriched, Original or Vanilla, soy milk which provided $47 \mathrm{mg}$ of isoflavonoid per $8 \mathrm{oz}$ serving. The patients received three $8 \mathrm{oz}$ servings per day in an open label, nonblinded fashion. No dose escalation or reduction was 
Table I: Demographic, Clinical, and Pathologic Characteristics of 20 men with biochemical recurrent prostate cancer after previous therapy

\begin{tabular}{|c|c|c|c|c|c|c|c|}
\hline Patient No. & Age (yr.) & Race & $\begin{array}{l}\text { Serum PSA at } \\
\text { Initial Diagnosis } \\
(\mathrm{ng} / \mathrm{ml})\end{array}$ & $\begin{array}{l}\text { Gleason Score at } \\
\text { Initial Diagnosis }\end{array}$ & $\begin{array}{l}\text { Clinical Stage at } \\
\text { Initial Diagnosis }\end{array}$ & Initial Treatment & $\begin{array}{l}\text { Length of F/U } \\
\text { months }\end{array}$ \\
\hline I & 62 & White & UNK & $3+4=7$ & T3aNxMx & RP & 12 \\
\hline 2 & 67 & White & 4.8 & $3+3=6$ & $\mathrm{~T} 2 \mathrm{xNxMx}$ & $\begin{array}{c}\text { Brachy/EBRT/ } \\
\text { ADT }\end{array}$ & 12 \\
\hline 3 & 67 & White & UNK & $3+3=6$ & $\mathrm{~T} 2 \mathrm{xNxMx}$ & RP & 12 \\
\hline 4 & 78 & White & 4.7 & $3+4=7$ & $\mathrm{~T} 2 \mathrm{aN} x \mathrm{Mx}$ & $\begin{array}{c}\text { Brachy/EBRT/ } \\
\text { ADT }\end{array}$ & 6, started ADT \\
\hline 5 & 77 & African American & 14.08 & UNK & T3aNxMx & RP/EBRT & 12 \\
\hline 6 & 75 & White & 8.28 & $4+5=9$ & $\mathrm{~T} 2 \mathrm{cN} x \mathrm{Mx}$ & ADT/RP & 12 \\
\hline 7 & 69 & White & 10.36 & $3+3=6$ & TIcNxMx & EBRT & 12 \\
\hline 8 & 71 & White & UNK & UNK & UNK & RP/Salvage EBRT & 12 \\
\hline 9 & 75 & White & UNK & $4+4=8$ & $\mathrm{~T} 2 \mathrm{bN} \times \mathrm{Mx}$ & EBRT/ADT & 12 \\
\hline 10 & 77 & White & 8.1 & $4+5=9$ & $\mathrm{~T} 3 \mathrm{bN} \times \mathrm{Mx}$ & RP & 3 , started ADT \\
\hline $1 I^{*}$ & 79 & White & UNK & $2+3=5$ & TIcNxMx & EBRT & $\begin{array}{l}\text { 9, withdrew due } \\
\text { to side effects }\end{array}$ \\
\hline 12 & 68 & White & UNK & $4+4=8$ & $\mathrm{~T} 2 \mathrm{a} N x \mathrm{Mx}$ & $\begin{array}{l}\text { RP/Adjuvant } \\
\text { EBRT }\end{array}$ & 6, started ADT \\
\hline 13 & 76 & African American & 11.13 & $3+3=6$ & $\mathrm{~T} 2 \mathrm{aN} \times \mathrm{Mx}$ & EBRT & 12 \\
\hline 14 & 79 & White & 4.0 & $3+4=7$ & TIcNxMx & $\begin{array}{l}\text { RP/Adjuvant } \\
\text { EBRT }\end{array}$ & 12 \\
\hline 15 & 73 & White & 10 & $3+2=5$ & TIcNxMx & EBRT & 12 \\
\hline 16 & 60 & White & 9.2 & $3+4=7$ & TIcNxMx & $\begin{array}{l}\text { RP/Adjuvant } \\
\text { EBRT }\end{array}$ & 12 \\
\hline 17 & 63 & White & 17.3 & $4+3=7$ & TIcNxMx & EBRT & 12 \\
\hline 18 & 70 & White & 9.8 & $3+3=6$ & $\mathrm{~T} 2 \mathrm{xNxMx}$ & RP/salvage EBRT & 12 \\
\hline $19 *$ & 76 & African American & 4.1 & $3+4=7$ & $\mathrm{~T} 2 \mathrm{bN} \times \mathrm{Mx}$ & $\mathrm{RP}$ & 6, lost to $F / U$ \\
\hline 20 & 77 & White & 8.7 & UNK & $\mathrm{T} 2 \mathrm{aN} x \mathrm{Mx}$ & EBRT & 6, lost to $F / U$ \\
\hline Median & 73 & -- & 9.2 & 7 & --- & --- & 12 \\
\hline
\end{tabular}

*, noncompliant

Brachy, brachytherapy

EBRT, external beam radiation therapy

$\mathrm{RP}$, radical prostatectomy

ADT, androgen deprivation therapy

F/U, follow-up

planned. Compliance was assessed by counting empty soy milk containers and verified by presence of soy components in serum samples.

Pretreatment evaluation included a complete medical history, physical examination (including digital rectal examination), serum PSA, free/total testosterone, lipids, serum isoflavone levels (genistein, daidzein, and equol), and assessment of quality of life (Functional Assessment of Cancer Treatment-Prostate, FACT-P questionnaire). Furthermore, whole blood was obtained prior to initiation of the study to assess for DNA polymorphism. Follow-up serum PSA levels to assess efficacy were obtained at 3, 6, 9 , and 12 months after initiation of treatment. Medical history, physical examination, serum testosterone, lipids, isoflavone, and quality of life were assessed at 6 and 12 months after initiation of treatment.
Quality of life prior to and during therapy was measured by the FACT-P questionnaire, which consists of 38 items calculated to evaluate functional impairment and the perceived effect of that impairment on quality of life. The instrument assesses overall and specific aspects of quality of life in five domains (i.e. physical, functional, social, emotional, and prostate related). These include selfreported ability to perform normal physical and social activities, attitude towards self and future, level of physical well-being, and quality of support from friends, family and health care providers. The measure was used to assess the impact of the dietary intervention on quality of life.

At least three pretherapy serum PSAs were available for each subject to compute pretherapy PSA slope. Next, PSA had been measured within days of the time the patient was enrolled in the study. This level was used as study 
entry level. PSA serum level was measured again 3 months after enrollment in the study, after 6 months, and after 12 months. PSA outcome was evaluated in two ways: a) how response changed over time [i.e. slope of line log (PSA) study entry versus 3 months, versus 6 months, versus 12 months of treatment], and b) as a change on the calculated PSA doubling time before treatment versus PSA doubling time after 3 months, 6 months, and 12 months of treatment. PSA doubling time was calculated using the following formula: PSA doubling time $=\log 2 \times \mathrm{t} /$ $[\log ($ final PSA) - $\log$ (initial PSA)]. Because pretherapy PSA levels were compared to posttherapy PSA levels, each subject could serve as his own control.

Patients were allowed to continue on therapy until a) they exhibited evidence of PSA progression (as defined by two successive increases in their PSA with an absolute increase of at least 30\% above baseline), b) they had clinical evidence or radiographic evidence of distant metastases, or c) patient/physician opted to stop therapy.

\section{Isoflavone Analysis}

A complete LC-MS analysis of patient serum samples for genistein, daidzein and equol (total and aglycone) was performed. The serum samples were both sulfate and glucuronide conjugates which requires hydrolysis with a mixed $\beta$-glucuronidase and sulfatase enzyme preparation (Helix pomatia; Sigma Chemicals, St Louis, MO) to determine total versus free isoflavone. For each sample, an aliquot was analyzed directly for free isoflavones, while another was enzymatically hydrolysed to determine total isoflavones. Quantitative isoflavone analysis was accomplished using reversed-phase HPLC with UV and mass spectral detection in series [12]. Briefly, samples were prepared for analysis by mixing with ammonium acetate buffer and formic acid prior to multiple extractions in ethyl acetate. Pooled extracts were dried under nitrogen and resuspended in $0.5 \mathrm{ml}$ of 50:50 acetonitrile: $0.2 \%$ aqueous formic acid. Samples were then injected onto an Apollo C18 column (Alltech, Deerfield, IL) with Alltech Adsorbosphere HS C18 guard column in a Hewlett-Packard 1100 series liquid chromatograph system (Wilmington, DE). Separation occurred under a linear gradient with mobile phase B ( $0.1 \%$ formic acid in acetonitrile) increasing from $40 \%$ to $60 \%$ over $60 \mathrm{~min}$. Mobile phase A was $0.1 \%$ formic acid in water. The flow rate was $0.40 \mathrm{ml} / \mathrm{min}$ with column temperature of $40^{\circ} \mathrm{C}$. Free isoflavones and deconjugated glucosides were detected for quantitation using an HP variable wavelength UV detector at $260 \mathrm{~nm}$ and quantified against an external standard series. Identification was confirmed using the Finnigan LCQ Ion Trap Mass Spectrometer (Finnigan MAT, San Jose, CA) in positive ion mode with electrospray ionization. Extraction efficiency was determined using the isoflavone biochanin
A, with phenolphthalein-glucuronide as deconjugation surrogate.

\section{Genomic DNA Isolation \& Evaluation of AR CAG Polymorphisms}

Whole blood was obtained from patients and DNA extracted utilizing QiAamp DNA blood kit (Qiagen, Valencia, CA). Nested PCR reaction was utilized to amplify the CAG polymorphism on the AR gene. Primers for AR gene were designed using Primer Express software (PE-Applied Biosystems). Outside primers for CAG was constructed: 5'-GTGCGCGAAGTGATCCAGAA-3' and 5'TCTGGGACGCAACCTCTCTC-3' and inside primers $5^{\prime}$ AGAGGCCGCGAGCGCAGCACCTC-3'-fam and 5'-GCTGTGAAGGTTGCTGTTCCTCAT-3'. The inside forward primer was labeled with fluorescent 6-carboxy-fluorescein (FAM). The first PCR reaction consisted of 17 cycles $\left(94^{\circ} \mathrm{C}\right.$ for $1 \mathrm{~min}, 55^{\circ} \mathrm{C}$ for $1 \mathrm{~min}$, and $72^{\circ} \mathrm{C}$ for $30 \mathrm{sec}$ ). The nested PCR used $1 \mu \mathrm{l}$ of the first PCR product and amplified further for 28 cycles $\left(94^{\circ} \mathrm{C}\right.$ for $1 \mathrm{~min}, 66^{\circ} \mathrm{C}$ for $1 \mathrm{~min}$, and $72^{\circ} \mathrm{C}$ for $1.5 \mathrm{~min}$ ). Screening for AR mutations was performed using single-strand conformation polymorphism (SSCP) of PCR amplified AR genomic DNA. The radio-labeled PCR fragment identified above was analyzed by nondenaturing polyacrylamide gel electrophoresis [13]. Fragments showing an aberrant PCR-SSCP pattern on gel were subjected to direct DNA sequencing to document the exact nucleotide base deletion, addition, or change.

\section{Statistical analysis}

A mixed regression model was used to compare the slope of PSA after study entry to that before study entry. The PSA levels for a given patient were treated as repeated measurements and the uniform correlation between PSA measurements was assumed. The slopes before and after study entry were globally compared using all data points in the mixed model. In addition, the slope of PSA after study entry was compared to that before study entry for each individual patient by regular regression analysis. The PSA doubling time before study entry was computed by tog2/ [log(PSA at entry) - $\log$ (initial PSA)] and the PSA doubling time after study entry was computed by tog2/ [log(last PSA) - $\log$ (PSA at entry)]. Note that the PSA doubling time can be negative if the denominator is negative. The PSA doubling times before and after study entry were compared by the sign test based on paired data. The Wilcoxon signed rank test was performed for other chemistries (Table 2) and QOL. The correlation between AR gene CAG polymorphisms and PSA levels at 12 months after study entry was evaluated by the Spearman's correlation coefficient. All reported p-values were 2-sided. All data were analyzed using SAS version 9.1.3 software. 
Table 2: Serum PSA, Testosterone, and Cholesterol Before and During Study

\begin{tabular}{|c|c|c|c|c|c|c|c|c|c|c|}
\hline Pt No. & $\begin{array}{l}\text { PSA at } \\
\text { entry } \\
(n g / m l)\end{array}$ & $\begin{array}{l}\text { PSA at } \\
12 \\
\text { months } \\
\text { (ng/ml) }\end{array}$ & $\begin{array}{l}\text { Free PSA } \\
\text { at entry } \\
(\mathrm{ng} / \mathrm{ml})\end{array}$ & $\begin{array}{l}\text { Free PSA } \\
\text { at I } 2 \\
\text { months } \\
\text { (ng/ml) }\end{array}$ & $\begin{array}{l}\text { Testoster } \\
\text { one at } \\
\text { entry (ngl } \\
\text { ml) }\end{array}$ & $\begin{array}{l}\text { Testoster } \\
\text { one at I } 2 \\
\text { months } \\
(\mathrm{ng} / \mathrm{ml})\end{array}$ & $\begin{array}{l}\text { Free } \\
\text { Testoster } \\
\text { one at } \\
\text { entry (ngl } \\
\text { ml) }\end{array}$ & $\begin{array}{l}\text { Free } \\
\text { Testostero } \\
\text { ne at I2 } \\
\text { months } \\
\text { (ng/ml) }\end{array}$ & $\begin{array}{l}\text { Choleste } \\
\text { rol at } \\
\text { entry } \\
\text { (mg/dl) }\end{array}$ & $\begin{array}{l}\text { Cholester } \\
\text { ol at I } 2 \\
\text { months } \\
\text { (mg/dl) }\end{array}$ \\
\hline I & 0.57 & 1.93 & 0.10 & 0.381 & 493 & 468 & N/A & 10.1 & 195 & 207 \\
\hline 2 & 0.50 & 0.35 & 0.08 & 0.007 & 331 & 382 & 46.7 & 8.5 & 148 & 134 \\
\hline 3 & 1.76 & 1.62 & $\mathrm{~N} / \mathrm{A}$ & N/A & 259 & 263 & 11.9 & $\mathrm{~N} / \mathrm{A}$ & 229 & N/A \\
\hline 4 & 1.17 & $\mathrm{~N} / \mathrm{A}$ & 0.11 & $\mathrm{~N} / \mathrm{A}$ & 508 & N/A & 9.3 & $\mathrm{~N} / \mathrm{A}$ & 109 & N/A \\
\hline 5 & 6.87 & 11.23 & $\mathrm{~N} / \mathrm{A}$ & 1.690 & 324 & 299 & $\mathrm{~N} / \mathrm{A}$ & 5.7 & 203 & 173 \\
\hline 6 & 5.94 & $13.4 \mid$ & 0.83 & 2.250 & $\mathrm{~N} / \mathrm{A}$ & 418 & $\mathrm{~N} / \mathrm{A}$ & 9.7 & 140 & 134 \\
\hline 7 & 1.18 & 1.73 & N/A & 0.280 & 264 & 118 & $\mathrm{~N} / \mathrm{A}$ & 5.5 & 162 & $|4|$ \\
\hline 8 & 0.67 & $\mathrm{~N} / \mathrm{A}$ & 0.08 & N/A & 264 & N/A & 10.2 & $\mathrm{~N} / \mathrm{A}$ & 167 & N/A \\
\hline 9 & 0.15 & 0.12 & 0.01 & $\mathrm{~N} / \mathrm{A}$ & 68 & 68 & 3.4 & $\mathrm{~N} / \mathrm{A}$ & 260 & 197 \\
\hline 10 & 0.4 & $\mathrm{~N} / \mathrm{A}$ & $\mathrm{N} / \mathrm{A}$ & $\mathrm{N} / \mathrm{A}$ & 360 & $\mathrm{~N} / \mathrm{A}$ & $\mathrm{N} / \mathrm{A}$ & $\mathrm{N} / \mathrm{A}$ & N/A & N/A \\
\hline II & 18.86 & $\mathrm{~N} / \mathrm{A}$ & $\mathrm{N} / \mathrm{A}$ & $\mathrm{N} / \mathrm{A}$ & 137 & N/A & 4.6 & $\mathrm{~N} / \mathrm{A}$ & 199 & N/A \\
\hline 12 & 11.21 & $\mathrm{~N} / \mathrm{A}$ & 1.49 & $\mathrm{~N} / \mathrm{A}$ & 204 & $\mathrm{~N} / \mathrm{A}$ & $\mathrm{N} / \mathrm{A}$ & $\mathrm{N} / \mathrm{A}$ & 134 & N/A \\
\hline 13 & 0.74 & 0.67 & 0.07 & N/A & 565 & N/A & 15.6 & N/A & 319 & N/A \\
\hline 14 & 3.49 & 3.90 & 0.22 & 3.902 & 280 & 265 & 10.4 & 9.7 & $|5|$ & 145 \\
\hline 15 & 1.36 & 1.59 & $\mathrm{~N} / \mathrm{A}$ & $\mathrm{N} / \mathrm{A}$ & 521 & 487 & 19.3 & $\mathrm{~N} / \mathrm{A}$ & 255 & 235 \\
\hline 16 & 0.50 & 0.50 & $\mathrm{~N} / \mathrm{A}$ & 0.020 & $\mathrm{~N} / \mathrm{A}$ & 281 & $\mathrm{~N} / \mathrm{A}$ & 12.0 & N/A & 200 \\
\hline 17 & 2.67 & 5.15 & 0.15 & 0.290 & 287 & 382 & 9.8 & 0.9 & 180 & 170 \\
\hline 18 & 0.59 & 1.10 & N/A & 0.100 & 333 & 317 & 4.0 & 47.6 & 147 & 163 \\
\hline 19 & 1.04 & $\mathrm{~N} / \mathrm{A}$ & N/A & N/A & $\mathrm{N} / \mathrm{A}$ & N/A & $\mathrm{N} / \mathrm{A}$ & N/A & N/A & N/A \\
\hline 20 & 0.79 & 1.05 & N/A & N/A & 299 & N/A & 10.5 & N/A & 116 & $17 \mid$ \\
\hline Median & I.II & 1.61 & 0.11 & 0.19 & 299 & 308 & 10.3 & 9.7 & 167 & $17 \mid$ \\
\hline$P$ value & 0.081 & & 0.285 & & 0.064 & & 0.031 & & 0.806 & \\
\hline
\end{tabular}

\section{Results}

\section{Subjects' characteristics}

Twenty men with biochemical recurrent prostate cancer were enrolled. Table 1 shows the demographic, clinical, and pathologic characteristics of the cohort. Compliance was estimated to be high with only two subjects noted not to ingest the required amount of soy milk. Six men did not complete the study: 1 due to side effects, 2 were lost to follow-up, and 3 began ADT. One of the men who had initiation of ADT did so despite no significant increase in serum PSA. The other two patients had a significant increase in serum PSA (PSA doubling time $<3$ months). The two non-compliant patients were among the six men who dropped out of the study.

\section{PSA level - Reduction}

Six patients achieved $8 \%, 9 \%, 20 \%, 23 \%, 30 \%$ and $70 \%$ reduction in PSA after the treatment, respectively. In addition, one patient had no change in PSA. The remaining 13 patients had increased PSA.

\section{PSA level - Comparison of Slopes}

The slopes of PSA after study entry were compared to that before study entry in a mixed regression model as described in the statistical analysis section. The PSA levels for a given patient were treated as repeated measurements and the uniform correlation between PSA measurements were assumed. Within the mixed regression model, it was estimated that PSA had increased 56\% per year before study entry and PSA increased $20 \%$ per year for the 12 month study period $(p=0.05)$. There were 6 drop-outs: four had PSA measurements up to 9 months and two had PSA measurements up to 6 months. Since the mixed regression model has the ability to incorporate missing data, the six drop-outs were included in the analysis.

The slope of PSA after study entry was also compared to that before study entry for each individual patient. It was found that the slope of PSA after study entry was significantly lower than that before study entry in 6 patients $(p$ $<0.05)$ and the slope of PSA after study entry was significantly higher than that before study entry in 2 patients ( $p$ $<0.05)$. For the remaining 12 patients, the change in slope was insignificant (Figure 1). In two drop-outs, the PSA slopes after study entry were significantly higher than that before study entry; in other two drop-outs, the PSA slopes after study entry were significantly lower than that before study entry; in the remaining two drop-outs, the differences in PSA slope were not statistically significant. Dropouts are noted by "D" on Figure 1. 


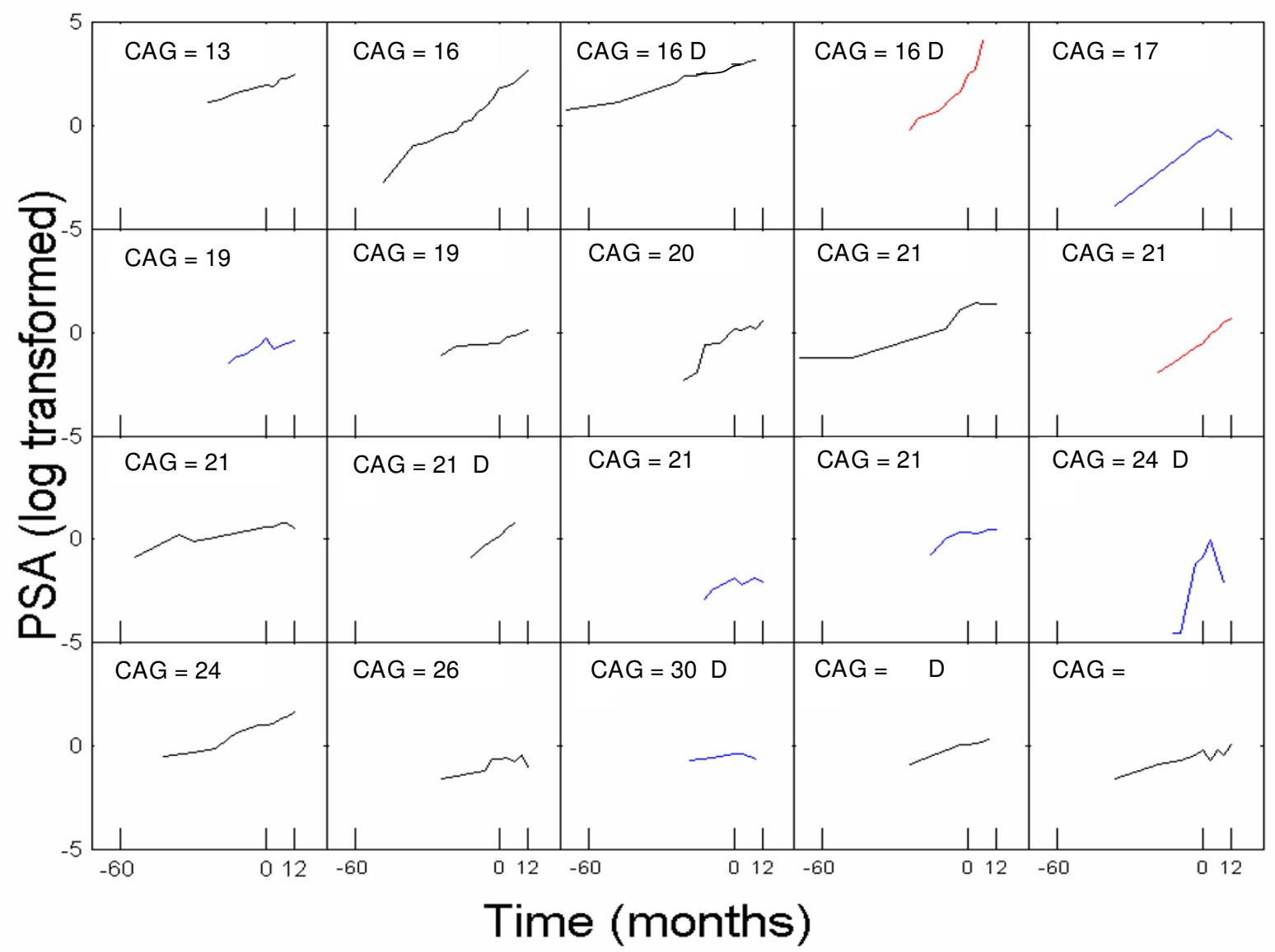

Figure I

PSA levels in logarithm scale for each patient. Blue line $(N=6)$ represents the slope of PSA during isoflavone therapy was significantly lower than that before the therapy, red line $(N=2)$ represents the slope of PSA during isoflavone therapy was significantly higher than that before the therapy and black line $(N=12)$ represents the slope of PSA during isoflavone therapy was unchanged than that before the therapy. CAG, CAG androgen receptor polymorphisms. D, subject who dropped out before completion of the therapy.

\section{PSA doubling time}

Changes in PSA after study entry were compared to that before study entry in terms of doubling time. The PSA doubling times before and after study entry were computed for each patient. PSA doubling times were positive in all patients (median = 15 months) before study entry, i.e. PSA levels at study entry were higher than the initial PSA levels. In contrast, the PSA doubling time was negative during the therapy in 6 patients. Note that the doubling time was negative if the last PSA level was lower than the PSA level at study entry. In addition, one patient had no change in PSA and the doubling time was undefined. The PSA doubling time was positive during the therapy for the remaining 13 patients (median $=15$ months). Among the 13 patients, 7 had PSA doubling times longer than that before study entry. Improvements have been seen in 14 patients in terms of PSA doubling time ( $p=0.044$, sign test).

\section{Other chemistries}

Free testosterone decreased while on therapy (median 10.3 vs. $9.7 \mathrm{ng} / \mathrm{ml}, p=0.031$ ). However, neither total testosterone nor cholesterol level was significantly manipulated during isoflavone therapy (Table 2).

\section{Isoflavone Level and AR Molecular Weight}

Median total genistein, daidzein, and equol prior to the start of therapy were $<0.002,0.012$, and $0.023 \mu \mathrm{g} / \mathrm{ml}$, respectively. Serum isoflavone levels measured at 6 months are depicted in Table 3. Among 16 men with 
Table 3: Total and Free Serum Isoflavones and Androgen Receptor CAG repeat

\begin{tabular}{|c|c|c|c|c|}
\hline Patient No. & Total Genistein $(\mu \mathrm{g} / \mathrm{ml})$ & Total Daidzein $(\mu \mathrm{g} / \mathrm{ml})$ & Total Equol $(\mu \mathrm{g} / \mathrm{ml})$ & Androgen Receptor CAG repeat \\
\hline 1 & 0.709 & 0.735 & 0.115 & 21 \\
\hline 2 & 1.284 & 0.660 & 0.063 & 26 \\
\hline 3 & 0.189 & 0.468 & 0.331 & 21 \\
\hline 4 & 0.555 & 0.409 & 0.306 & 21 \\
\hline 5 & 0.102 & 0.572 & 0.523 & 13 \\
\hline 6 & 0.739 & 0.468 & 0.039 & 16 \\
\hline 7 & 2.071 & 0.602 & 0.329 & 20 \\
\hline 8 & $\mathrm{~N} / \mathrm{A}$ & $\mathrm{N} / \mathrm{A}$ & $\mathrm{N} / \mathrm{A}$ & 30 \\
\hline 9 & 0.022 & 0.014 & 0.020 & 21 \\
\hline 10 & $N / A$ & $\mathrm{~N} / \mathrm{A}$ & N/A & 24 \\
\hline II & 0.023 & 0.568 & $<0.001$ & 16 \\
\hline 12 & 0.186 & 0.063 & 0.061 & 16 \\
\hline 13 & $<0.002$ & 0.005 & 0.048 & 19 \\
\hline 14 & 0.058 & 0.192 & 0.050 & 21 \\
\hline 15 & 1.049 & 0.580 & 0.188 & 21 \\
\hline 16 & 0.492 & 0.170 & 0.062 & 17 \\
\hline 17 & 1.989 & 0.817 & 0.492 & 24 \\
\hline 18 & $<0.002$ & 0.021 & 0.119 & 19 \\
\hline 19 & $\mathrm{~N} / \mathrm{A}$ & N/A & N/A & N/A \\
\hline 20 & $N / A$ & N/A & N/A & N/A \\
\hline Median & 0.524 & 0.468 & 0.115 & --- \\
\hline
\end{tabular}

N/A, not assessed (adequate sample unable to be obtained) $\mu \mathrm{g}$, microgram

available data, 12 men (75\%) demonstrated significant (> $2 \times \mathrm{CTL}, \mathrm{CTL}=0.023 \mu \mathrm{g} / \mathrm{ml}$ ) levels of total equol and 10 of $16(63 \%)$ had significant $(>2 \times \mathrm{CTL}, \mathrm{CTL}=0.009 \mu \mathrm{g} /$ $\mathrm{ml})$ levels of free equol present in serum. In the study cohort, median genistein level was $0.524 \mu \mathrm{g} / \mathrm{ml}$ (range < 0.002 to 2.071 ), median daidzein levels was $0.468 \mu \mathrm{g} / \mathrm{ml}$ (range 0.005 to 0.817 ), and median equol level was 0.115 $\mu \mathrm{g} / \mathrm{ml}$ (range $<0.001$ to 0.523 ). Median free genistein level was $0.012 \mu \mathrm{g} / \mathrm{ml}$ (range $<0.002$ to 0.019 ), median free daidzein level $0.016 \mu \mathrm{g} / \mathrm{ml}$ (range 0.003 to0.434), and median free equol level was $0.040 \mu \mathrm{g} / \mathrm{ml}$ (range $<0.001$ to 1.328 ). The correlations of free equol and total equol with PSA level at 12 months were 0.11 and 0.39 , respectively ( $\mathrm{p}$-values $=0.71$ and 0.19 ). Correlations of genistein (free and total) and daidzen (free and total) with PSA level at 12 months were not significant either.

There were 9 documented AR gene CAG polymorphisms in our cohort (Table 3). Eight men had $\leq 20$ CAG repeat. A longer CAG polymorphism was associated with a lower PSA level at 12 months after study entry (Spearman's correlation coefficient $=-0.63, p=0.05$ ) and a slower rise in PSA over time (Figure 2).

\section{Quality of Life}

There was no significant difference in the five domains of the FACT-P between pretherapy and on therapy (Figure $3)$. Side effects were minimal. One patient of $20(5 \%)$

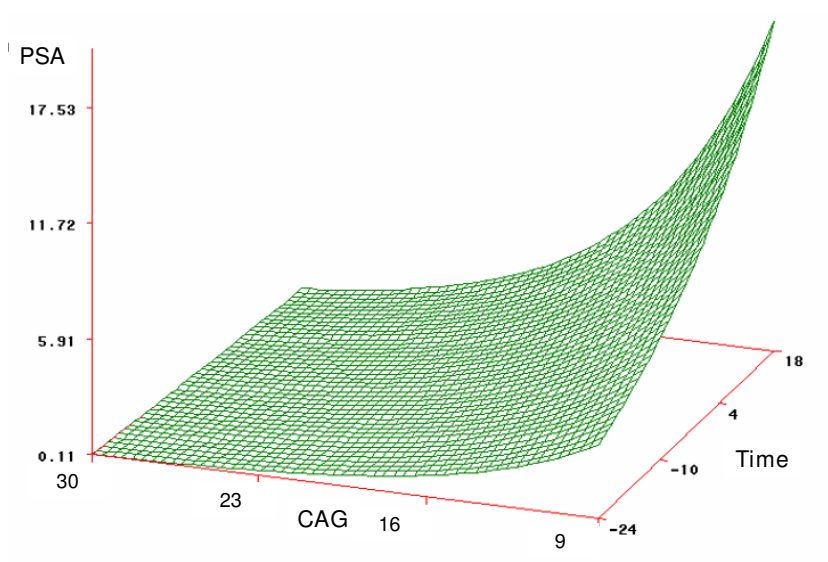

Figure 2

Effect of PSA vs. CAG Polymorphism MW over Time. MW, molecular weight.

reported diarrhea and withdrew from the study. No other side effects were reported.

\section{Discussion}

Numerous phase I and II clinical trials have studied men with biochemical recurrence (PSA only) prostate cancer after previous therapy. To date no randomized clinical trial has demonstrated a survival advantage of salvage 


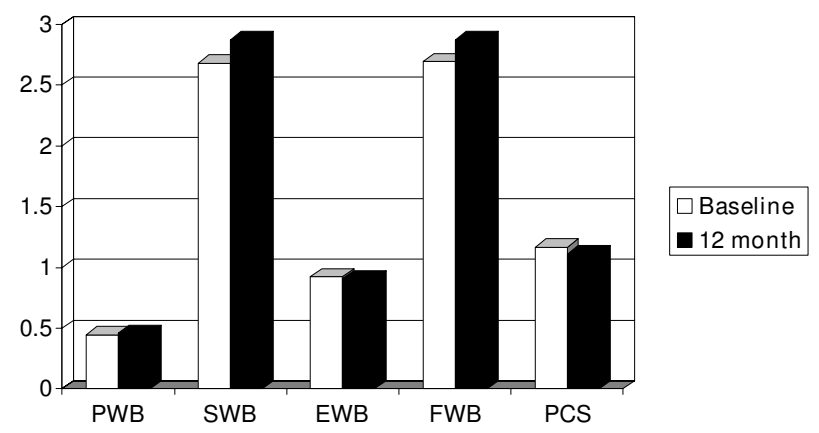

Figure 3

Baseline (white) and 12 month (black) FACT-P Quality of Life questionnaire in $\mathbf{2 0}$ men with biochemical recurrent prostate cancer after previous therapy. (PWB, physical well being; SWB, social well being; EWB, emotional well being; FWB, functional well being; PCS, prostate cancer specific).

therapies in this cohort. Thus, these men pose a difficult therapeutic dilemma. The majority of them are asymptomatic. Therapeutic maneuvers with hormonal ablation, chemotherapy, and experimental agents may have significant side effects. It is a difficult to persuade an asymptomatic man to begin a potential toxic regimen with unknown benefit. Because of these reasons, men with PSA only recurrence are excellent candidates for effective holistic regimens. The goal of such treatment is to delay or prevent disease progression and thereby prolong the time until ADT. Furthermore, slowing the rate of PSA rise may have an effect on overall survival.

We treated 20 men with $141 \mathrm{mg}$ of isoflavone per day for 12 months. Our dose regimen was based on 1) 22 randomized studies performed to assess cardiovascular disease[14] and 2) ease of administration (1-8 oz glass of soy milk for breakfast, lunch, and dinner). Because the only sign of recurrent disease after failed therapy was rising serum PSA profile, PSA response was the primary end point measure of our study. In general, serum PSA levels at study entry were not significantly different after 12 months of therapy (mean 3.02 vs. mean 3.17, respectively). Of the 20 patients, the slope of PSA after study entry was significantly lower than that before study entry in 6 patients, significantly higher than that before study entry in 2 patients, and unchanged in the remaining 12 patients. Thus, we were able to demonstrate a decline in the rise of serum PSA after the initiation of soy milk, thus demonstrating isoflavones biologic activity in prostate cancer patients. Furthermore responders started with a lower serum PSA level.
Several novel phase II non-randomized clinical trials have been reported in patients with biochemical recurrent prostate cancer. 1,25-dihydroxyvitamin D3 can result in differentiated cancer cells and induce apoptosis [15]. Gross and others demonstrated that $0.5 \mu \mathrm{g}-2.5 \mu \mathrm{g}$ of 1,25dihydroxyvitamin D3 (Calitriol) daily slowed the rate of serum PSA rise in 6 of 7 patients. Unfortunately, hypercalciuria developed in all patients, with one developing a renal calculus and another developing renal insufficiency [16]. It is possible that the precursor to 1,25-dihydroxyvitamin D3, 25 hydroxyvitamin D3 may be administered with significantly less side effects. Research suggests that the prostate, similar to the kidney, possesses the enzyme to convert 25-hydroxyvitamin D3 to 1,25-dihydroxyvitamin D3, thus enabling it to exert their effect [17]. Next, Woo reported 9 out of 15 patients with PSA relapse prostate cancer after definitive therapy had stable or decreasing serum PSA levels when treated with 2,000 IU (50 $\mu \mathrm{g})$ of 25-dihydroxyvitamin D3 (cholecalciferol) daily. No adverse side effects were reported [18]. Pruthi and others reported the effects of celecoxib (COX-2 inhibitor) 400 mg given orally twice daily in 40 men with PSA recurrent prostate cancer after definitive treatment. Eleven men had a decline in serum PSA and 8 had a stabilization of PSA. One patient was removed from the study for a presumed transient ischemic attack [19]. Researchers from Wake Forest reported that $15-120 \mathrm{mg} /$ day of lycopene supplementation was safe and well tolerated in a cohort of 36 men with PSA recurrent prostate cancer. However, no serum PSA responses were observed and $37 \%$ of patients had PSA progression [20].

Hussain and others reported on a heterogeneous group of men with prostate cancer who were treated with $100 \mathrm{mg}$ of soy isoflavone (Novasoy) twice daily for a maximum of 6 months. There was a decrease in the rate of the rise of serum PSA in men with PSA recurrent disease. The rates of rise decreased from $14 \%$ to $6 \%$ while on study [21]. These results are consistent with our study, where the rates of rise decreased from $56 \%$ to $20 \%$ while on study. Our more favorable results may be due to longer treatment duration ( 6 months vs. 12 months). Taken together, the data from the two clinical trials in men with PSA recurrent prostate cancer treated with isoflavone are encouraging and should be further studied. Ideally these studies should be combined with genomics or proteomics assays to 1) determine the profile of treatment responders, and 2) attempt to elucidate mechanistic pathways that can be exploited by combining these agents with other holistic drugs or with a more conventional therapy.

Isoflavones in the soy milk included genistein and daidzein. Numerous studies have demonstrated the cytostatic and cytotoxic effect of genistein in various malignancies including breast, lung, melanoma, prostate, head and 
neck squamous cell carcinoma, leukemia, and lymphoma [22]. Genistein has a heterocyclic diphenolic structure similar to estrogen [22]. Because of the similar structure, it is proposed that soy (genistein) exerts its effect on cells by interacting with hormone receptors. The exact mechanism of genistein's anti-tumoral effects is unknown. Proposed mechanisms are perturbations in cell cycle, decreased proliferation, decreased angiogenesis, and increased apoptosis. In addition to genistein and daidzein, another metabolite of isoflavone is equol. Equol is produced via the bacterial conversion of the soy isoflavone daidzein in the intestines [23]. It is estimated that approximately $30 \%$ of Americans can convert diadzein to equol, however the real percentage is unknown seeing that no large study has assessed this in the general American population. The percentages are higher $(>80 \%)$ in Chinese and Japanese. Similar to the other isoflavone metabolite, equol has a chemical structure related to estrogen and is known to interact with estrogen receptors [23]. Over two-thirds of the men in our study were able to convert daidzein to equol. Overall, median total equol level was $0.115 \mu \mathrm{g} / \mathrm{ml}$ (range $<0.001$ to 0.523 ) and median free equol level was $0.040 \mu \mathrm{g} / \mathrm{ml}$ (range $<0.001$ to 1.328). There could be genetic differences in isoflavone metabolism in each racial group, however due to the small numbers this could not be assessed.

The CAG repeat polymorphisms of the androgen receptor gene have been associated with an increased prostate cancer risk and the repeat length has been correlated with cancer stage and grade at presentation [24]. Investigators have also correlated CAG repeat polymorphism of the AR gene to response to ADT [25]. Similarly, in this small study, we demonstrated that subjects with CAG polymorphisms molecular weight $>22$ were more likely to respond to the experimental therapy (Figure 2). In future studies, CAG polymorphisms may be used to determine eligibility into these trials (i.e., subjects with CAG polymorphisms $\geq 22$ will be enrolled). Due to the small numbers in the current study, we could not correlate CAG polymorphisms with equol production which could be a fascinating correlation.

There are several limitations to this study. First, this is a small study that was terminated early due to poor accrual. The planned power of $60 \%$ was not attained. It is possible that with a larger number of subjects, a more significant change in serum PSA while on therapy could have been demonstrated. Furthermore there was a substantial drop out rate in this study. Previous studies have commented on the difficulty of performing clinical trials in an innercity population such as ours $[26,27]$. In addition, this phase II study did not have a control group and the therapy was neither randomized nor blinded. Though not ideal, this study design which was employed by other groups [16,18-20] would provide useful data on the feasibility and utility of isoflavone in this cohort prior to embarking on a larger, costly phase II or even phase III study. Last, serum PSA was the primary endpoint of this study. We acknowledge the limitations of serum PSA in this study (i.e., fluctuations). But to date there are no other prognostic markers for prostate cancer in this cohort. To decrease the chance of detecting 'noise' (or common fluctuations of serum PSA levels), we assessed not absolute PSA but PSA trends. Nevertheless, the results of this study suggest biologic activity with the isoflavone diet in men with biochemical recurrent prostate cancer

\section{Conclusion}

Our findings show that isoflavone was a well-tolerated alternative to expectant management or early ADT in men with biochemical recurrent prostate cancer. Isoflavone may slow the rate of increase of serum PSA in a subset of patients with biochemical progression after radiation therapy or radical prostatectomy. The findings reported herein warrant further investigation in a larger cohort of patients. In these larger studies, correlative biomarkers should be explored to assist with elucidating a possible mechanism of action with isoflavones in prostate cancer.

\section{Competing interests}

The authors declare that they have no competing interests.

\section{Authors' contributions}

JMP was study coordinator, WWT physician of 9 patients who assisted with recruitment and follow-up, SA performed CAG portion of the project, MC and WH were statisticians, KTS assisted with interpretation of isoflavone serum levels, CJR was study PI.

\section{Acknowledgements}

20 men who participated in this study \& Hain-Celestial, Denver CO for providing the soy milk.

\section{References}

I. Pienta KJ, Esper PS: Risk factors for prostate cancer. Ann Intern Med 1993, I I 8:793.

2. Dunn JE: Cancer epidemiology in population of the United States. Cancer Res 1975, 35:240.

3. Haenszel W, Kurihoro M: Studies of Japanese migrants. J Natl Cancer Inst 1968, 40:43.

4. Shemizer H, Ross RK, Berstein L, Yatane R, Henderson BE, Mack TM: Cancer of prostate and breast among Japanese and white immigrants in Los Angeles county. Br J Cancer I991, 63:963.

5. Messina M, Persky V, Setchell KDR, Barnes S: Soy intake and cancer risk: a review of in vitro and in vivo data. Nutr Cancer 1994, 2I:II3.

6. Akiyama $\mathrm{T}$, Ogawara $\mathrm{H}$ : Use and specificity of genistein as an inhibitor of protein-tyrosine kinases. Methods Enzymol 1991, 20I:362.

7. Coward L, Barnes NC, Setchell KDR, Barnes S: Genistein and daidzein and their B-glycoside conjugates; anti-tumor isoflavones in soybean foods of the American and Asian diets. J Agric Food Sci 1993, 41: 1961.

8. Watanabe T, Shiraishi T, Saasaki H, Oishi M: Inhibitors for protein tyrosine kinases, ST638 and genistein, induce differentiation 
of mouse erythroleukemia cells in a synergistic manner. Exp Cell Res 1989, 183:335.

9. Magee PJ, Raschke M, Steiner C, Duffin JG, Pool-Zobel BL, Jokela T, et al.: Equol: a comparison of the effects of the racemic compound with that of the purified S-enantiomer on the growth, invasion, and DNA integrity of breast and prostate cells in vitro. Nutr Cancer 2006, 54:232.

10. Andersson P, Varenhorst E, Soderkvist P: Androgen receptor and vitamin $D$ receptor gene polymorphisms and prostate cancer risk. Eur J Cancer 2006, 42(16):2833-7.

II. American Society for Therapeutic Radiology and Oncology Consensus Panel: Consensus statement: guidelines for PSA following radiation therapy. Int J Radiat Oncol Biol Phys 1997, 37:1035.

12. Coward L, Kirk M, Albin N, Barnes S: Analysis of plasma isoflavones by reversed-phase HPLC multiple reaction ion monitoring-mass spectrometry. Clin Chim Acta 1996, 247:121.

13. Ruizeveld de Winter JA, Janssen PLJ, Sleddens HM, Verleun-Mooijman MC, Trapman J: Androgen receptor status in localized and locally progressive hormone refractory human prostate cancer. Am J Path 1994, 144:735.

14. Sacks FM, Lichtenstein A, Van Horn L, Harris W, Kris-Etherton P, Winston M: American Heart Association Nutrition Committee. Soy protein, isoflavones, and cardiovascular health: an American Heart Association Science Advisory for professionals from the Nutrition Committee. Circulation 2006, I I3:1034.

15. Whitlatch LW, Young MV, Schwartz GG, Flanagan JN, Burnstein KL, Lokeshwar BL, et al.: 5-Hydroxyvitamin D-Ialpha-hydroxylase activity is diminished in human prostate cancer cells and is enhanced by gene transfer. J Steroid Biochem Mol Biol 2002, $8 I(12): 135$.

16. Gross C, Stamey T, Hancock S, Feldman D: Treatment of early recurrent prostate cancer with 1,25-dihydroxyvitamin D3 (Calcitriol). J Urol 1998, 159:2035.

17. Schwartz GG, Whitlatch LW, Chen TC, Lokeshwar BL, Holick MF: Human prostate cells synthesize I,25-dihydroxyvitamin D3 from 25-hydroxyvitamin D3. Cancer Epidemiol Biomarkers Prev 1998, 7(5):391.

18. Woo TC, Choo R, Jamieson M, Chander S, Vieth R: Pilot study: potential role of Vitamin $D$ (Cholecalciferol) in patients with PSA relapse after definitive therapy. Nutr Cancer 2005, 5 I:32.

19. Pruthi RS, Derksen JE, Moore D, Carson CC, Grigson G, Watkins C, et al.: Phase II trial of celecoxib in prostate-specific antigen recurrent prostate cancer after definitive radiation therapy or radical prostatectomy. Clin Cancer Res 2006, I 2:2172.

20. Clark PE, Hall MC, Borden LS Jr, Miller AA, Hu JJ, Lee WR, et al.: Phase I-II prospective dose-escalating trial of lycopene in patients with biochemical relapse of prostate cancer after definitive local therapy. J Urol 2006, 67:1257.

21. Hussain M, Banerjee M, Sarkar FH, Djuric Z, Pollack MN, Doerge D, et al: Soy isoflavones in the treatment of prostate cancer. Nutr Cancer 2003, 47: III.

22. Adlercreutz CH, Goldin BR, Gorbach SL, Hockerstedt KA, Watanabe $S$, Hamalainen EK, et al.: Soybean phytoestrogen intake and cancer risk. J Nutr 1995, I 25:757S. Erratum in: J Nutr 1995; 125(7): 1960

23. Niculescu MD, Pop EA, Fisher LM, Zeisel SH: Dietary isoflavones differentially induce gene expression changes in lymphocytes from postmenopausal women who form equol as compared with those who do not. J Nutr Biochem in press. 2006; Sept 7

24. Nam RK, Elhaji Y, Krahn MD, Hakimi J, Ho M, Chu W, et al.: Significance of the CAG repeat polymorphism of the androgen receptor gene in prostate cancer progression. J Urol 2000, 164(2):567.

25. Klotz L, Correia A, Zhang W: The relationship between the androgen receptor CAG repeat polymorphism length and the response to intermittent androgen suppression therapy for advanced prostate cancer. Prostate Cancer Prostatic Dis 2005, 8: 179 .

26. Baquet CR, Commiskey P, Daniel Mullins C, Mishra SI: Recruitment and participation in clinical trials: socio-demographic, rural/ urban, and health care access predictors. Cancer Detect Prev 2006, 30:24-33.

27. Blumenthal DS, Sung J, Coates R, Williams J, Liff J: Recruitment and retention of subjects for a longitudinal cancer prevention study in an inner-city black community. Health Serv Res 1995 , 30:197-205.

\section{Pre-publication history}

The pre-publication history for this paper can be accessed here:

\section{http://www.biomedcentral.com/1471-2407/8/132/pre} pub
Publish with Bio Med Central and every scientist can read your work free of charge

"BioMed Central will be the most significant development for disseminating the results of biomedical research in our lifetime. "

Sir Paul Nurse, Cancer Research UK

Your research papers will be:

- available free of charge to the entire biomedical community

- peer reviewed and published immediately upon acceptance

- cited in PubMed and archived on PubMed Central

- yours - you keep the copyright
BiolMedcentral 